\title{
Tuberculous Endocarditis Complicated with Acute Respiratory Distress Syndrome: A Case Report
}

Yuichi Nakamura $^{1^{*}}$, Hiroyuki Kunii ${ }^{1}$, Akiomi Yoshihisa ${ }^{1}$, Akihiko Sato ${ }^{1}$, Masashi Kamioka ${ }^{1}$, Kazuhiko Nakazato ${ }^{1}$, Hitoshi Suzuki ${ }^{1}$, Shu-ichi Saitoh ${ }^{1}$, Shinichi Hisa $^{2}$, and Yasuchika Takeishi ${ }^{1}$

${ }^{1}$ Department of Cardiology and Hematology, Fukushima Medical University, Japan

${ }^{2}$ Department of Cardiology, Masu Memorial Hospital, Japan

*Corresponding author: Yuichi Nakamura, MD, Department of Cardiology and Hematology, Fukushima Medical University1 Hikarigaoka, Fukushima 960-1295, Japan Tel: +81-24-547-1190, Fax: +81-24-548-1821. E-mail: u1naka@fmu.ac.jp

Received date: Mar 28, 2014, Accepted date: May 21, 2014, Published date: May 26, 2014

Copyright: (c) 2014 Nakamura Y, et al. This is an open-access article distributed under the terms of the Creative Commons Attribution License, which permits unrestricted use, distribution, and reproduction in any medium, provided the original author and source are credited.

\begin{abstract}
A 61 years-old woman treated with methylprednisolone due to arthritis mutilans was admitted to our hospital after being found to have complete atrioventricular block and vegetation on the mitral and aortic valves. Infective endocarditis was suspected, but offending bacteria was not detected by repetitive blood cultures. Despite intensive care, we could not control the infection and she died of complication of acute respiratory distress syndrome on the eleventh day. Autopsy findings revealed epitheloid cell granulomas and Mycobacterium tuberculosis in the heart. Therefore, she was diagnosed with tuberculous endocarditis.
\end{abstract}

Keywords Mycobacterium tuberculosis; Infective endocarditis; Acute respiratory distress syndrome

\section{Introduction}

Myobacterium tuberculosis infection is a re-emerging infectious disease. There were 1.4 million deaths from tuberculosis in 2012 accoding to WHO [1]. However, tuberculous endocarditis is very rare, and the diagnosis of this disease is very difficult owing to slow growth of myocardium tuberculosis. Tuberculous endocarditis is mainly reported in miliary tuberculosis or after valve replacement using an infected prosthetic valve [2-6]. Furthermore, tuberculous endocarditis has been reported mainly from autopsy. We report a case of tuberculous endocarditis complicated with acute respiratory distress syndrome (ARDS).

\section{Case Report}

The patient was a 61 year-old woman treated with methylprednisolone due to arthritis mutilans for 33 years. She did not have a history of tuberculosis and abnormality of chest X-ray. She had multiple histories of hemiplegia of temporary duration during 1 month before admission. She did not have respiratory symptoms, and was admitted with nausea, hemiplegia and vertigo to her nearby hospital. The woman was found to have complete atrioventricular block with ventricular escape beats of $60 \mathrm{bpm}$ on electrocardiogram (Figure 1), and vegetation on the mitral valve was detected by echocardiography. Infective endocarditis was suspected, so the patient was transferred to our hospital by ambulance. She was admitted to the intensive care unit in our hospital.

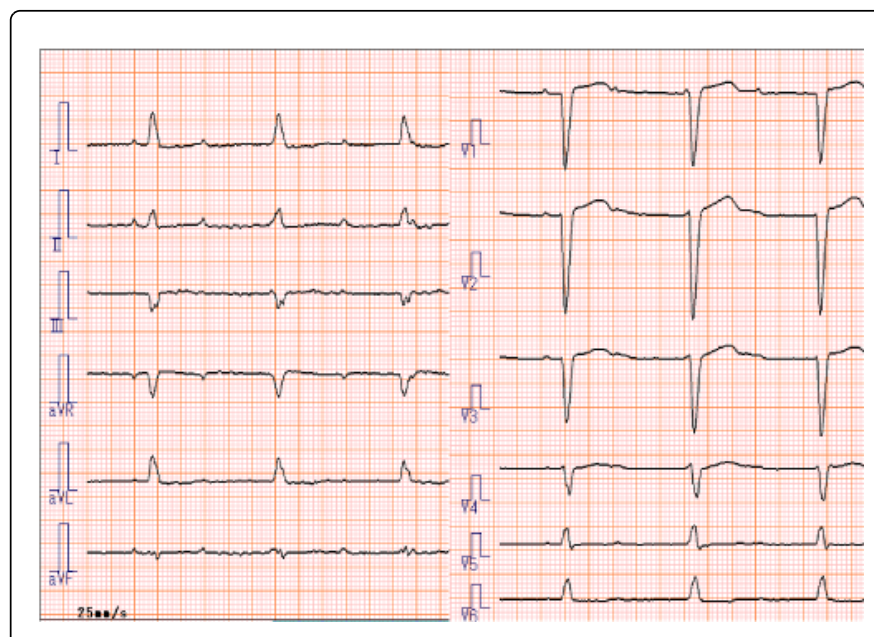

Figure 1: Electrocardiogram at admission. Complete AV block was observed.

A physical examination at the time of admission revealed a body temperature of $37.4^{\circ} \mathrm{C}$, a pulse rate of 67 beats $/ \mathrm{min}$ and blood pressure of $167 / 103 \mathrm{mmHg}$. A systolic murmur of grade III was present at the apex, and no pulmonary rales were audible. Laboratory studies revealed a white blood cell count of $9600 / \mu \mathrm{l}(2800<$ normal $<8300 / \mu \mathrm{l})$, the C-reactive protein level was $1.89 \mathrm{mg} / \mathrm{dl}$ (normal<0.3 $\mathrm{mg} / \mathrm{dl}$ ), total protein was $5.2 \mathrm{~g} / \mathrm{dl}(6.7<$ normal $<8.3 \mathrm{~g} / \mathrm{dl})$, and albumin was $2.2 \mathrm{~g} / \mathrm{dl}$ $(3.9<$ normal $<4.9 \mathrm{~g} / \mathrm{dl})$. The serial cardiac enzyme level was normal, eGFR was $230 \mathrm{ml} / \mathrm{min} / 1.73 \mathrm{~m}^{2}$, and her level of brain natriuretic peptide (BNP) was $666.9 \mathrm{pg} / \mathrm{mL}$ (normal $<18.4 \mathrm{pg} / \mathrm{mL}$ ). On a chest Xray, the cardiothoracic ratio was $66 \%$ and slight pulmonary edema was observed. Brain magnetic resonance imaging did not reveal freshly- 
formed cerebral infarction. Echocardiography showed that left ventricular wall motion was normal, and vegetation was observed on the anterior mitral leaflet and non-coronary cusp of the aortic valve (Figure 2).

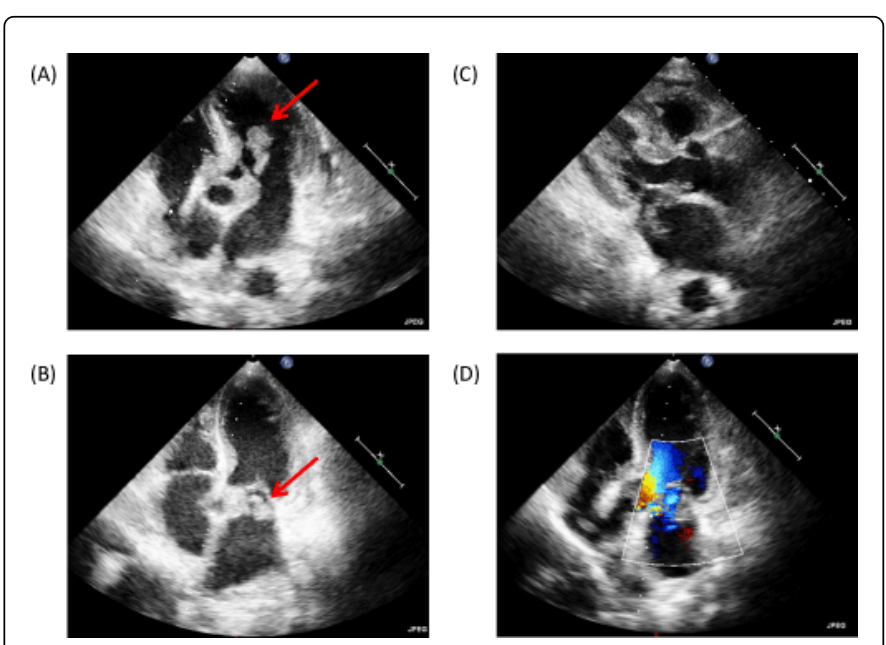

Figure 2: Transthoracic echocardiography at admission. Vegetation was observed on the anterior mitral leaflet (arrow). (A) Fourchamber view at diastolic phase; (B) four-chamber view at systolic phase; (C) long axis view; (D) Color Doppler image showed mild mitral regurgitation.

We performed a total of 3 sets of blood culture studies on the 1st day of admission. We started antibiotic administration with meropenem at a dose of $0.5 \mathrm{~g}$ every 8 hours. But high-grade fever persisted and inflammatory signs did not improve, so we changed the antibiotics to $2 \mathrm{~g}$ /day of ceftriaxone and $400 \mathrm{mg}$ /day of amikacin on the 4th day of admission. However, she developed hypotension with no inflammatory improvement. We added dopamine, albumin and gamma globulin on the 5th day. On the 9th day, results of blood cultures performed on the 1st day were negative. So we preformed 3 sets of blood culture studies again. Her respiratory status worsened and chest X-ray revealed widespread diffuse infiltrates involving both lung fields. She received noninvasive ventilation (BiPAP Vision, Respironics, Inc., Murrysville, PA) with an inspiratory/expiratory positive airway pressure of $10 / 5 \mathrm{~cm}$ of $\mathrm{H}_{2} \mathrm{O}$ with a $\mathrm{FiO}_{2}$ of 0.6 , but her arterial blood showed $\mathrm{PaO}_{2}$ of $73.0 \mathrm{mmHg}$. Since her left ventricular wall motion and the levels of BNP were not different compared with those on admission. According Berlin definition, we considered the case was complicated by ARDS. We added sivelestat to treat ARDS, but she died from septic shock and respiratory failure on the 11th day. The patient's family consented to an autopsy. The results of blood cultures performed on the 9th day were available after she died and were negative.

Histopathology of both lungs and vegetations revealed epithelioid cell granuloma with multinucleated giant cells showing central caseous necrosis (Figure 3A). Acid-fast bacilli were found in the granuloma of Ziehl-Neelsen staining (Figure 3B). In 1935, Baker advocated three criteria for tuberculous endocarditis: 1) microscopic evidence of tuberculous reaction; 2) positive tubercle bacilli staining; 3) and exclusion of other causes of endocardial lesions [7]. The patient met these criteria, and our diagnosis was tuberculous endocarditis. The histopathological findings of the lungs revealed hyaline membranes and intra-alveolar edema presented in whole lobes of both lungs.

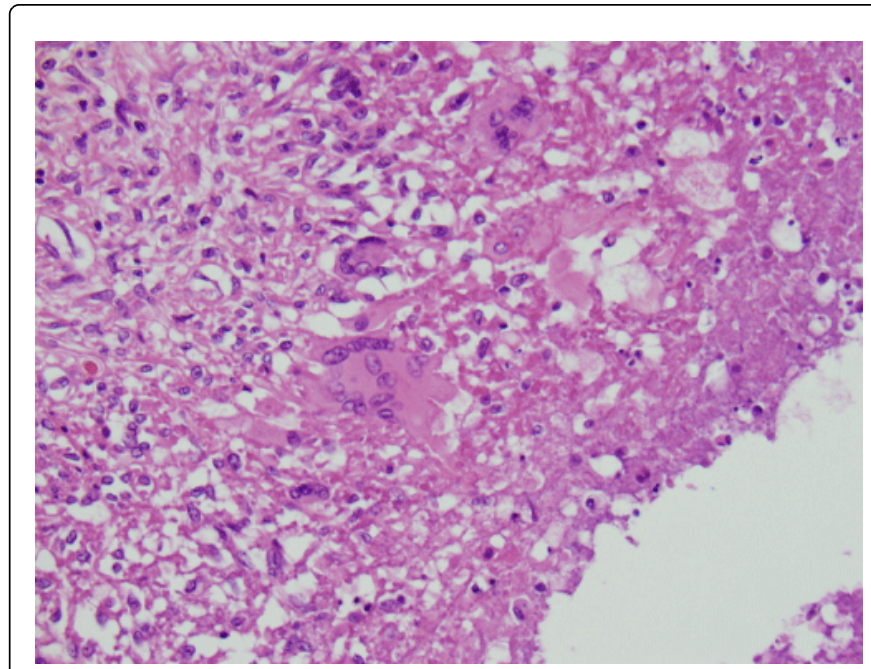

Figure 3: Histopathology image of vegetation of the mitral valve. (A) Haematoxylin-eosin staining of epithelioid cell granuloma with multinucleated giant cells showing central caseous necrosis.

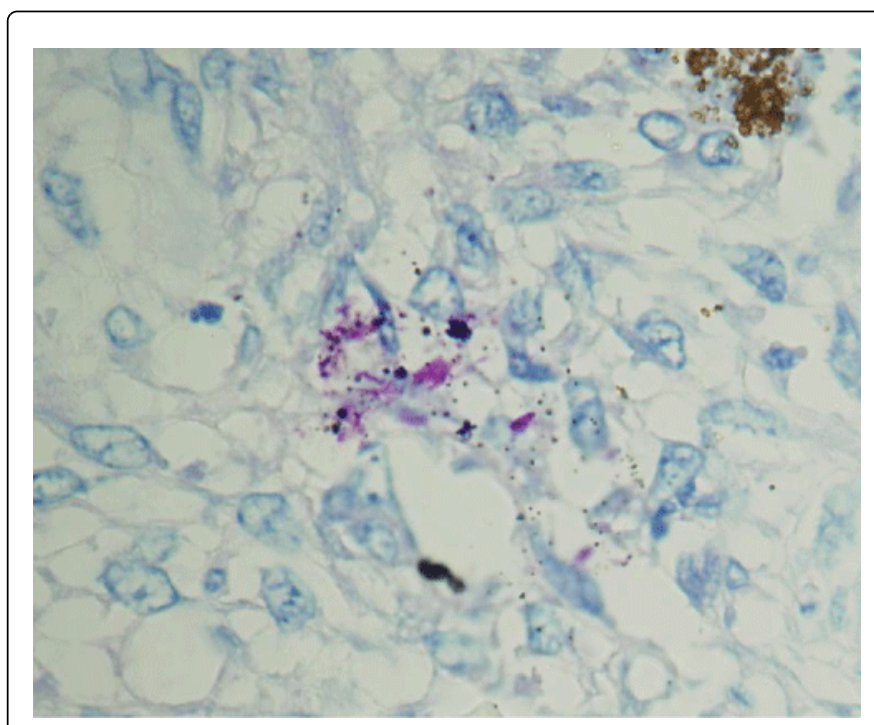

Figure 3B: Ziehl-Neelsen staining of acid-fast bacilli in granuloma.

\section{Discussion}

Tuberculous endocarditis is rare, but has been known since Laennec first reported cardiac tuberculosis in 1826. Raviart [8] had reported that $0.62 \%$ cases in a historical series of 7,683 cases of tuberculosis involved myocardial tuberculosis. Histopathological findings of epitheloid cells and giant cells are necessary to diagnose tuberculous endocarditis, but it is difficult to diagnose this disease in life because of the slow growth of the mycobacterium tuberculosis. Polymerase chain reaction may be helpful for diagnosis, but it has not been reported in tuberculous endocarditis [9]. QuantiFERON-TB Gold test X may also be of assistance.

Tuberculous endocarditis presents with non-specific symptoms, such as fever, weight-loss, general malaise and anorexia. Tuberculous 
Citation: $\quad$ Nakamura Y, Kunii H, Yoshihisa A, Sato A, and Kamioka M et al. (2014) Tuberculous Endocarditis Complicated with Acute Respiratory Distress Syndrome: A Case Report. J Gen Pract 2: 160. doi:10.4172/2329-9126.1000160

Page 3 of 3

endocarditis is correlated with non-specific ECG change and arrhythmias, such as in this patient [10].

Miliary tuberculosis is known to be associated with ARDS. ARDS caused by miliary tuberculosis was reported to have higher mortality rates than any other cases [11]. In the most of the reports, miliary tubercules in the lung were considered causal factors of ARDS [12]. Miyoshi et al. reported that patient without pulmonary tuberculosis developed ARDS secondary to extensive tissue damage due to extrapulmonary miliary tuberculosis [13].

Immunocompromised hosts are at risk for tuberculous endocarditis such as patient with human immunodeficiency virus positive or glucocorticoid administration like this patient [4]. Chronic and systemic glucocorticoid use reduces CD4 T-cell function to product cytokines such as interleukin-2 (IL), IL-4, tumor necrosis factor and interferon- $\gamma$. This loss of cytokines reduces B-cell production, which product antibodies. These changes lead impaired immune response to the infection of Mycobacterium tuberculosis [14]. Recently, tuberculous endocarditis has been reported in immunocomponent patients without miliary tuberculosis [15]. Such patients underwent valve replacement, and were diagnosed by sample from their valves. Antituberculous drugs are administered. But this patient could not have undergone surgical treatment, due to her condition. The suspicion was tuberculous infection. Tuberculous endocarditis is very rare, but should be suspected in not only immunocompromised patients, but also immunocompetent patients.

\section{References}

1. WHO (2012) Global Tuberculosis Report 8-28.

2. Kapoor OP, Mascarenhas E, Rananaware MM, Gadgil RK (1973) Tuberculoma of the heart. Report of 9 cases. Am Heart J 86: 334-340.
3. Kannangara DW, Salem FA, Rao BS, Thadepalli H (1984) Cardiac tuberculosis: TB of the endocardium. Am J Med Sci 287: 45-47.

4. Cope AP, Heber M, Wilkins EG (1990) Valvular tuberculous endocarditis: a case report and review of the literature. J Infect 21: 293-296.

5. Anyanwu CH, Nassau E, Yacoub M (1976) Miliary tuberculosis following homograft valve replacement. Thorax 31: 101-106.

6. Yamane H, Fujiwara T, Doko S, Inada H, Nogami A, et al. (1989) [Two cases of miliary tuberculosis following prosthetic valve replacement]. Kokyu To Junkan 37: 803-805.

7. Baker RD (1935) Endocardial tuberculosis. Arch Pathol 19: 611-635.

8. Raviart, G (1906) La tuberculose du myocarde. Arch. de méd. expér 29: 141.

9. Liu A, Nicol E, Hu Y, Coates A (2013) Tuberculous endocarditis. Int J Cardiol 167: 640-645.

10. Gouley BA, Bellet S, Mcmillan TM (1933) Tuberculosis of the myocardium. Arch Intern Med 51: 244-263.

11. Lee K, Kim JH, Lee JH, Lee WY, Park MS, et al. (2011) Acute respiratory distress syndrome caused by miliary tuberculosis: a multicentre survey in South Korea. Int J Tuberc Lung Dis 15: 1099-1103.

12. Murray HW, Tuazon CU, Kirmani N, Sheagren JN (1978) The adult respiratory distress syndrome associated with miliary tuberculosis. Chest 73: 37-43.

13. Miyoshi I, Daibata M, Kuroda N, Taguchi H, Enzan H (2005) Miliary tuberculosis not affecting the lungs but complicated by acute respiratory distress syndrome. Intern Med 44: 622-624.

14. Orme IM, Andersen P, Boom WH (1993) $\mathrm{T}$ cell response to Mycobacterium tuberculosis. J Infect Dis 167: 1481-1497.

15. Klingler K, Brändli O, Doerfler M, Schluger N, Rom WN (1998) Valvular endocarditis due to Mycobacterium tuberculosis. Int J Tuberc Lung Dis 2: 435-437. 